\title{
Pleural Fluid Bilirubin to Serum Bilirubin Ratio, comparison with Light's Criteria.
}

*Manoj Kumar Yadav ${ }^{1}$, Anusmriti Pal ${ }^{2}$, Anjal Bisht ${ }^{3}$,Jiwan Thapa $^{3}$

${ }^{1}$ Nepal Police Hospital, Pulmonary \& Critical Care Medicine, Kathmandu, Nepal ${ }^{2}$ Karnali Academy of Health Sciences, Medicine, Jumla, Nepal ${ }^{3}$ Bir Hospital, Kathmandu, Nepal.

\begin{abstract}
Introduction: Pleural fluid bilirubin and pleural fluid bilirubin to serum bilirubin ratio evaluation had been reported by several in distinguishing exudative from transudative pleural effusions along with Light's Criteria. The aim of this study was to assess whether pleural fluid bilirubin to serum bilirubin ratio, was a sensitive marker in classifying the pleural effusion as exudative and transudative and its correlation with Light's criteria.
\end{abstract}

Methods: A cross-sectional, observational study of Pleural fluid bilirubin to serum bilirubin ratio $\geq 0.6$ for exudates was taken and compared with Light's criteria overall and its individual parameters to classify exudative and transudative along with the diagnosis. Statistical analysis was done using SPSS 16, Sensitivity, specificity, Positive predictive value (PPV), Negative predictive value (NPV) and diagnostic accuracy of each tests were calculated.

Results: By diagnosis on discharge out of 86 samples of pleural effusion, 78(90.69\%) were exudative and $8(9.3 \%)$ were transudative effusion. Among transudative effusion, 72 were classified correctly and 6 were misclassified by pleural fluid Lactate dehydrogenase $(\mathrm{LDH})>2 / 3^{\text {rd }}$ of serum LDH criteria and out of 8 transudative, 4 were misclassified as exudative. When the pleural fluid to serum bilirubin ratio $\geq 0.6$ was used to differentiate, it categorized 67 as exudative effusion by pleural fluid LDH $>2 / 3^{\text {rd }}$ of serum LDH criteria and 11 were misclassified as transudative. This criterion had a sensitivity, specificity, PPV and NPV of $85.53 \%, 50 \%, 92.88 \%$ and $27.78 \%$ respectively with a significant $p$ value of $<0.01$.

Conclusion: The pleural fluid to serum bilirubin ratio can serve as an alternative easy and cost-effective diagnostic tool in differentiating between exudative and transudative pleural effusion. Though, it misclassified 11 exudative pleural fluids as transudative and 4 transudative as exudative. By taking Light's criteria as a standard, pleural fluid bilirubin to serum bilirubin ratio $\geq 0.6$ was found to be inferior to the Light's criteria also in terms of sensitivity, specificity, PPV and NPV. Still the pleural fluid to serum bilirubin ratio can serve as an alternative easy and cost-effective diagnostic tool in differentiating between exudative and transudative pleural effusion in low resource settings.

KeyWords: Bilirubin, Pleural effusion, Light's Criteria.

*Corresponding author: doctormanojyadav@gmail.com 
Yadav et al. International Journal of Medicine and Biomedical Sciences 2021; 5(1): 1-5

\section{INTRODUCTION}

Pleural effusions are associated with a number of medical conditions causing fluid accumulation via differing yet synergistic mechanisms including increased pleural membrane permeability, increased pulmonary capillary pressure, decreased oncotic pleural pressure, and lymphatic obstruction. Pleural fluid analysis yields important diagnostic information in most cases. ${ }^{1}$ Light's criteria since 1972, had been universally accepted than any other criteria for differentiating transudates from exudates as a gold standard test for decades till now. ${ }^{2}$ Though, Light's criteria had adequate sensitivity having low specificity and 20-30\% of transudates had been misclassified as exudates. But, over last few years, many noted Light's criteria misclassify significant percentage of the transudative pleural effusions as exudative. Thus new differentiation criteria, including the pleura to-serum cholesterol ratio, the albumin gradient, the protein

gradient, the pleura-to serum bilirubin ratio had been under investigation. ${ }^{3}$ Pleural fluid bilirubin and pleural fluid bilirubin to serum bilirubin ratio evaluation had also been reported by several to find out the role of pleural fluid bilirubin and its ratio to serum bilirubin in distinguishing exudative from transudative pleural effusions along with Light's Criteria. ${ }^{4}$ The aim of this study was to assess whether pleural fluid bilirubin to serum bilirubin ratio, was a sensitive marker in classifying the Pleural Effusion as exudative and transudative and its correlation with Light's criteria.

\section{Materials and Methods}

This was a cross-sectional, observational study conducted in Bir Hospital among patients admitted in medicine department with clinical, imaging and sonographic evidence of unilateral pleural effusion from April 2014 to
January 2015, informed consent was obtained. Ethical approval was obtained from institutional review committee of National Academy of Medical Sciences (NAMS). Light's criteria for distinguishing pleural exudative and transudative was used (Exudative if one or more of the following criteria were met) ${ }^{2}$

1. Pleural fluid protein to serum protein ratio greater than 0.5

2. Pleural fluid lactate dehydrogenase $(\mathrm{LDH})$ to serum LDH ratio greater than 0.6

3. Pleural fluid LDH greater than two thirds of the upper limit of normal for the serum LDH

Patients with pleural effusion secondary to trauma, hydropneumothorax and not willing to give consent were excluded. Thoracocentesis was done under aseptic precautions either via direct needle aspiration or ultrasound guided tapping, $10 \mathrm{ml}$ of pleural fluid was obtained by a disposable plastic syringe. ${ }^{5}$ The blood \& pleural fluid specimen were collected for determining the study variables as well as other parameters necessary to confirm the diagnoses. The cases were followed in the inpatient departments to ensure their final diagnoses for effusion. Bilirubin determination in both serum and pleural fluid was done by Walter and Gerarde method, total protein was determined by Biuret reaction, LDH measurement was based on the method of Henry et al and samples were analysed in Erba Mannheim fully automated biochemical analyser. Pleural fluid bilirubin to serum bilirubin ratio $\geq$ 0.6 for exudates was taken to classify pleural fluid and compared with Light's criteria overall and individual parameters to classify exudates and transudates along with the diagnosis on discharge. ${ }^{6}$ Statistical analysis was done using SPSS 16, Sensitivity, specificity, Positive predictive value (PPV), Negative predictive value (NPV) and diagnostic accuracy of each tests were calculated. 
Yadav et al. International Journal of Medicine and Biomedical Sciences 2021; 7(1): 1-5

\section{Results}

A total of 86 patients were enrolled, out of which $48.8 \%$ male and $51.2 \%$ were female among them $45.95 \%$ were male smokers and $54.05 \%$ were female smoker. The minimum age was 17 years with maximum being 88 years, the average age being 46 years with standard deviation 20.6 .
Major symptoms were cough (100\%), haemoptysis (29.06\%), dyspnea $(83.72 \%)$, poor appetite $(82.55 \%)$, fever and chest pain (70.9\%), weight loss in $55.81 \%$, lymphadenopathy $(61.62 \%)$ with the $\mathrm{p}$ value of $<0.01$. The sensitivity, specificity, PPV and NPV of various parameters were analysed using Bayesian method (Table 1)

Table1. Showing Sensitivity, Specificity, PPV and NPV with regard to various parameters.

\begin{tabular}{|l|c|c|c|c|c|}
\hline \multicolumn{1}{|c|}{ Parameters } & Sensitivity & Specificity & PPV & NPV & p-value \\
\hline Pleural fluid to serum bilirubin ratio & $85.53 \%$ & $50 \%$ & $92.88 \%$ & $27.78 \%$ & $<0.01$ \\
\hline Pleural fluid serum protein ratio $>0.5$ & $93.59 \%$ & $62.5 \%$ & $96.05 \%$ & $50 \%$ & $<0.01$. \\
\hline Pleural fluid to serum LDH ratio $>0.6$ & $87.72 \%$ & $31.03 \%$ & $71.43 \%$ & $56.25 \%$ & $<0.01$ \\
\hline Pleural fluid LDH $>2 / 3^{\text {rd }}$ of serum LDH & $92.3 \%$ & $50 \%$ & $94.74 \%$ & $40 \%$ & $<0.001$ \\
\hline
\end{tabular}

Table 2 describes the pleural effusions which were misclassified as transudative or exudative according to the individual parameters as shown.

Table2. Number of cases misclassified by each parameter

\begin{tabular}{|l|c|c|}
\hline \multicolumn{1}{|c|}{ Parameters } & Exudative & Transudative \\
\hline Pleural fluid serum protein ratio $>0.5$ & $5 / 78(6.4 \%)$ & $3 / 8(37.5 \%)$ \\
\hline Pleural fluid to serum LDH ratio $>0.6$ & $22 / 78(28.21 \%)$ & $1 / 8(1.28 \%)$ \\
\hline Pleural fluid LDH> 2/3 ${ }^{\text {rd }}$ of serum LDH & $6 / 78(7.69 \%)$ & $4 / 8(50 \%)$ \\
\hline Pleural fluid to serum bilirubin ratio & $11 / 78(14.1 \%)$ & $4 / 8(50 \%)$ \\
\hline
\end{tabular}

For the categorization of exudative and transudative, two criteria were applied. By diagnosis on discharge out of 86 samples $78(90.69 \%)$ were exudative and $8(9.3 \%)$ were transudative. On the basis of Light's criteria, 85 (98.83\%) pleural effusions were found to be exudative and 1 transudative. By these two criterion's, all most all pleural exudates were found as exudates rather than transudates. On the basis of pleural fluid bilirubin to serum bilirubin ratio $\geq 0.6$ for classifying exudative and transudative pleural fluid, 70(81.39\%) out of 86 samples were exudative and 16 transudative. By taking Light's criteria as a standard, pleural fluid bilirubin to serum bilirubin ratio $\geq 0.6$ was found to be inferior to the Light's criteria as shown in table 3 .

Table 3: Pleural fluid bilirubin and serum bilirubin ratio with light's criteria

\begin{tabular}{|c|c|c|c|c|}
\hline Parameters & Sensitivity & Specificity & PPV & NPV \\
\hline Light's criteria & $91.76 \%$, & $100 \%$ & $100 \%$ & $12.5 \%$ \\
\hline Bilirubin & $87.18 \%$, & $75 \%$ & $97.14 \%$ & $37.5 \%$ \\
\hline
\end{tabular}




\section{Yadav et al. International Journal of Medicine and Biomedical Sciences 2021; 5(1): 1-5}

\section{Discussion}

One of the most common disease entity encountered by physicians worldwide is pleural effusion. The most frequently used Light's criteria, though still considered as a gold standard; often misclassify a transudative as exudative. The present study was undertaken to evaluate the efficacy of pleural fluid bilirubin and its ratio to serum levels in distinguishing pleural fluid transudates and exudates and its correlation with Light's criteria. Out of $86,48.8 \%$ male and $51.2 \%$ were female among which 78 (90.69\%) were exudative and 8 (9.3\%) transudative pleural effusion, among which most common cause of exudative was tuberculosis followed by parapneumonic effusion and malignancy, which was similar to the study by Hamal et al. ${ }^{7}$ The finding contrast with other studies as Prabhakaran R et al had 58\% males and $42 \%$ females $^{8}$ likewise Sunanda et al also revealed that the male patients outnumbered females in cases of pleural effusion. ${ }^{9}$ Agrawal et al study possessed 74 exudative (71.84\%) and 29 transudative (28.16\%) among 103 cases, commonest cause being pneumonia $35.92 \%$, followed by tubercular $23.3 \%$ lung malignancy $12.6 \%$, congestive heart failure $11.65 \%$ etc. $^{10}$

Light's Criteria, ratio of pleural protein to serum protein > 0.5 for exudates, 73 were correctly classified as exudative and 5 classified correctly as transudates with sensitivity, specificity, PPV and NPV of $93.59 \%, 62.5 \%, 96.05 \%$ and $50 \%$ respectively with a significant $\mathrm{p}$ value of $<0.01$ this result was comparable with study of Metintas Muzaffer, et al. ${ }^{11}$ Whereas in Agrawal et al study pleural fluid serum protein ratio revealed sensitivity, specificity, PPV and NPV of $90.59 \%, 89.65 \%, 95.89 \%$ and $86.66 \%$ respectively. ${ }^{10}$ In my study, pleural fluid bilirubin to serum bilirubin ratio $\geq 0.6$, misclassified $14.1 \%$ exudates and $50 \%$ transudates which were previously classified as exudates by pleural fluid to serum protein ratio $>0.5$ criteria. Whereas, Light's criteria classified $85(98.83 \%)$ pleural effusions as exudative and 1 transudative. Agrawal et al study, nine of the exudates $(12.16 \%)$ and two of the transudates (6.89\%) were misclassified using bilirubin ratio as the differentiating criteria. Similarly, light's criteria, eight of the exudates $(10.81 \%)$ failed to meet the criteria and were labelled as transudative whereas three of the transudates (10.34\%) fulfilled the criteria and misplaced as exudates. ${ }^{10}$

Thus, Light's criteria as a standard classification basis of pleural fluids as exudates and transudates, pleural fluid bilirubin to serum bilirubin ratio $\geq 0.6$ were found to be inferior. Light's criteria were found superior in terms of sensitivity, specificity, PPV and NPV than the pleural fluids to serum bilirubin ratio $\geq 0.6$.

\section{Conclusion}

Though Light's criteria is considered as gold-standard for differentiating between exudative and transudative pleural effusion, it takes into account the LDH levels which might not be feasible at times due lack of facility at peripheral level particularly in developing countries like us. The pleural fluid to serum bilirubin ratio can serve as an alternative easy and cost-effective diagnostic tool in differentiating between exudates and transudates. It misclassified 11 exudative pleural fluids as transudative and 4 transudative as exudative. - By taking Light's criteria as a standard, pleural fluid bilirubin to serum bilirubin ratio $\geq 0.6$ was found to be inferior to the Light's criteria also in terms of sensitivity, specificity, PPV and NPV.

\section{Conflict Of Interest: None}

\section{References}

1. Hassan T, Al-Alawi M, Chotirmall H S and McElvaney G N. Pleural Fluid Analysis: Standstill or a Work in Progress? Pulmonary Medicine. 2012, 1-8. doi:10.1155/2012/716235

2. Light RW, Macgregor MI, Luchsinger PC, Ball WC. Pleural effusions: the diagnostic separation of transudates and exudates. Annals of Internal Medicine.1972 (Oct 1); 77(4):507-13. 
3. Çirak A Kadri, Tekgul Serpil, Bilaceroglu Semra, Komurcuoglu Berna, Sonmez K Seher and Ozden Emel. Diagnostic value of pleural light's criteria, the protein gradient, and the albumin gradient alone or in combination in differentiation of exudates and transudates. IGHH. 2012; 26(2): 107-16.

4. Metintaş M, Alataş Ö, Alataş F, Çolak Ö, Özdemir $\mathrm{N}$, Erginel S. Comparative analysis of biochemical parameters for differentiation of pleural exudates from transudates: Light's criteria, cholesterol, bilirubin, albumin gradient, alkaline phosphatase, creatine kinase, and uric acid. Clinica Chimica Acta. 1997(Aug 29); 264(2):149-62.

5. Collins T, Sahn S. Thoracocentesis. Clinical value, complications, technical problems, and patient experience. CHEST Journal. 1987;91(6):817-22.

6. Meisel S, Shamiss A, Thaler M, Nussinovitch N, Rosenthal T. Pleural fluid to serum bilirubin concentration ratio for the separation of transudates from exudates. CHEST Journal. 1990;98(1):141-4.

7. Hamal A, Yogi K, Bam N, Das S, Karn R. Pleural fluid cholesterol in differentiating exudative and transudative pleural effusion. Pulmonary medicine. 2013. http://dx.doi.org/10.1155/2013/135036
8. Prabhakaran R, Balan K and Karthikeyan S. Efficacy of Total Pleural Fluid Bilirubin and Ratio to Serum Levels, Pleural Fluid Cholesterol and Total Protein Level in Diagnosing Pleural Effusion Exudates and Transudates and its Correlation with light's Criteria. IOSR Journal of Dental and Medical Sciences. 2017; 16 (4):67-70.

9. Sunanda V, Shravanthi K, Rao BP, et al. The diagnostic separation of transudates and exudates in pleural effusion.Journal of College of Medical Sciences-Nepal. 2011; 7(3):24-8.

10. Agrawal Pawan, Shrestha Man Tirtha, Prasad Narayan Pratap, Aacharya Prasad Ramesh and Gupta Priyanka. Pleural Fluid Serum Bilirubin Ratio for Differentiating Exudative and Transudative Effusions. J Nepal Med Assoc 2018; 56(211):662-5

11. Metintaş M, Alataş Ö, Alataş F, Çolak Ö, Özdemir N, Erginel S. Comparative analysis of biochemical parameters for differentiation of pleural exudates from transudates: Light's criteria, cholesterol, bilirubin, albumin gradient, alkaline phosphatase, creatine kinase, and uric acid. Clinica Chimica Acta. 1997;264(2):149-62. 